\title{
Questão social, política social e neodesenvolvimentismo:notas críticas
}

\author{
Social issue, and social policy neo- \\ developmentism:critical notes
}

\author{
Gabriela Nogueira Eduardo* \\ Hiago Trindade de Lira Silva*
}

\begin{abstract}
Resumo: O exército industrial de reserva no processo de produção capitalista é insuprimível sem a superação do capitalismo. Assim demonstrou Marx na lei geral da acumulação capitalista. Mas, alguns teóricos preferem acreditar que este sistema sócioeconômico conseguiu criar mecanismos para ultrapassar a desigualdade social, defendendo um discurso na advocacia das Políticas Sociais. Nesse contexto, o Brasil vem seguindo uma tendência econômica neodesenvolvimentista para combater os efeitos da crise capitalista atual. Destarte, pretendemos estudar a relação entre a Questão Social e as políticas sociais no cenário do neodesenvolvimentismo. Para tanto, apoiados no materialismo histórico-dialético, realizamos uma revisão de literatura, a partir das contribuições de intelectuais que vêm se dedicando a pensar a problemática ora esboçada, tais como: Leher (2012), Oliveira (2010), dentre outros. Concluímos o texto com algumas reflexões que demonstram o sentido e o delineamento das políticas sociais na atual conjuntura brasileira, nos marcos do Partido dos Trabalhadores (PT).
\end{abstract}

Palavras-chave: Questão Social. Política Social. Neodesenvolvimentismo.

\begin{abstract}
The reserve army of labor in the capitalist production process is irrepressible without the overthrow of capitalism. Thus Marx demonstrated in the general law of capitalist accumulation. But some theorists prefer to believe that this socio-economic system can create mechanisms to address social inequality, defending a speech in advocacy of Social Policies. In this context, Brazil is following a neo-developmentism economic trend to counter the effects of the current capitalist crisis. Thus, we intend to study the relationship between Social Issues and social policies in the setting of neo-developmentism. To do so, supported the historicaldialectical materialism, we conducted a literature review, from the contributions of intellectuals who has been dedicating to think the problems outlined herein, such as: Leher (2012), Oliveira (2010), among others. We conclude the text with
\end{abstract}

\footnotetext{
*Possui Graduação em Serviço Social pela Faculdade de Filosofia, Ciências e Letras de Cajazeiras. Mestranda do Programa de Pós-Graduação em Serviço Social, na Área de concentração Política Social na Universidade Federal da Paraíba (UFPB). Bolsista do Conselho Nacional de Desenvolvimento Científico e Tecnológico. E-mail: gabrielanogueira02@hotmail.com

"Possui Graduação em Serviço Social pela Universidade do Estado do Rio Grande do Norte. Mestrando do Programa de Pós Graduação em Serviço Social da Universidade Federal do Rio Grande do Norte. E-mail: hiagolira@hotmail.com
} 
some reflections that demonstrate the meaning and design of social policies in the current Brazilian situation, within the framework of the Workers Party.

Keywords: Social Issues. Social Policy. Neo-developmentism.

Recebido em: 11/11/2011. Aceito em: 20/11/2012.

\section{Introdução}

Na esteira das últimas quatro décadas, a sociedade foi acometida por transformações de dimensão mundial que ganharam corpo e se aprofundaram, consideravelmente, com a emergência da crise estrutural do capital, nos termos de Mészáros (2002). Apontamos algumas: o padrão taylorista-fordista, primeiramente nos países de capitalismo central, derruiu-se, junto aos últimos pilares que sustentavam o Estado de Bem-estar social e as garantias de certa "estabilidade" para a classe trabalhadora. Este padrão foi substituído pelo modelo Toyotista, incentivando uma nova maneira de gerir a organização da produção a pautar-se, sobretudo, na flexibilização das condições e relações de trabalho. No cenário político-institucional, os anos que demarcam a emergência desse sistema, vêm acompanhados pelo desenvolvimento do neoliberalismo: "um corpo de doutrina coerente, autoconsciente, militante, lucidamente decidido a transformar todo o mundo à sua imagem, em sua ambição estrutural e sua extensão internacional". (ANDERSON, 1995, p. 22).

Na particularidade brasileira, este sistema tem embalado o conjunto de ações de diversos governos. Certamente, o grau de intensidade e a forma com que o neoliberalismo vai sendo incorporado à realidade social variam de acordo com os princípios que movem esses governos. O certo é que, de FHC a Lula e Dilma, ele tem existido e, num mesmo instante, ocasionado rebatimentos diversos para a classe trabalhadora, a partir da complexificação da questão social associada a conformações das políticas sociais hoje, sob a égide do propalado neodesenvolvimentismo.

Essas principais mudanças no âmbito do trabalho corroboram para exponenciar a patama- res mais elevados a barbárie social, colocando à tona o desemprego e, com ele, novas questões que repousam em torno do tráfico de drogas, tráfico de crianças, exploração sexual e conflitos étnicos, questões essas ainda não muito latentes no período que antecede esses acontecimentos. (NETTO, 2010).

No lastro sócio-histórico a engendrar os acontecimentos supramencionados, alguns autores estão delineando investigações que apontam para afirmar a existência de uma Nova Questão Social, e essa perspectiva do debate ganha relevância, dentre outras questões, porque orienta uma formulação e desenvolvimento das políticas públicas dotando-as de um formato específico e, ao mesmo tempo, apontando saídas para a questão social no âmbito do Estado.

De modo geral, esses autores defendem que os problemas oriundos da contradição capitalista explicitada adiante, foram superados com o modelo de Estado de Bem-Estar Social implementado nos países europeus entre as décadas de 1930 e 1960. Esse período foi marcado pela expansão das políticas sociais, pleno emprego e conquistas de direitos sociais, criando a ilusão de que o capitalismo tinha conseguido encontrar a fórmula para eliminar a desigualdade social e suas manifestações expressas nos "problemas sociais" ${ }^{1}$. No entanto, a crise mundial e as transmutações no papel do Estado de Bem-Estar, servem-nos de base para desvelar suas contradições internas, ao passo em que, no momento de tensão, verificou-se um abandono das bases que

\footnotetext{
${ }^{1}$ As aspas se justificam na medida em que não queremos esconder ou negar a dimensão política inerente à questão social, como fizeram em outros tempos, atribuindo aos sujeitos individuais ou à sua família e comunidade a causa de seus problemas e "patologias". Um aprofundamento deste debate pode ser encontrado em Netto (1992), sobretudo quando o autor indica a passagem da questão social de problema privado para público, nos marcos do capitalismo monopolista.
} 
o conformavam. Em verdade, ele não deu conta de sanar a extrema pobreza e que a acumulação de poucos brota da superexploração da classe trabalhadora, como afirma a tese de Marx na lei geral da acumulação capitalista. (MARX, 2013).

Nesse sentido, desde meados da década de 1990 países periféricos como o Brasil tem se inserido nessa concorrência desenfreada por lucro. Dessa forma, vem lançando investimentos para a industrialização, ampliando o setor de serviços e revertendo sua base agrária de exportador de matéria-prima, com isso vem aumentando o PIB do país e a ampliação das políticas sociais. Esse conjunto de tendências se fez presente de maneira mais expressiva no governo liderado pelo Partido dos Trabalhadores, o que leva alguns autores a defender a existência do neodesenvolvimentismo. Temos como hipótese de estudo que a Questão Social e a Política Social estão colaborando para a reprodução do poder dos governos neodesenvolvimentistas no país.

Assim, o artigo intitulado "Questão Social, Política Social e Neodesenvolvimentismo", traz uma reflexão sobre os limites das políticas sociais e as suas principais tendências na particularidade brasileira, visto que, dentro da perspectiva da teoria social crítica, a superação da questão social é impossível sem a supressão do capital. Discute também os limites do próprio capitalismo diante da crise do capital, a fim de resgatar a perspectiva revolucionária como horizonte de uma nova sociabilidade como possibilidade.

\section{A Questão Social, A Lei da Acumulação Capitalista e a Crise do Capital}

A presente seção propõe-se a fazer, nos limites do texto que ora trazemos a público, uma aproximação da categoria Questão Social, sobremaneira, por meio da abordagem da lei de acumulação primitiva do capital, formulada por Marx no primeiro livro "O capital", na perspectiva de enquadrá-la como subsunção da contradição capital $x$ trabalho. Nesse sentido, analisamos os movimentos do capital e as transformações macro societárias verificadas nas últimas quatro décadas, na perspectiva de defender a atualidade do pensamento marxista na discussão proposta.

Na verdade, em toda a sua obra, o Marx nunca utilizou o termo "Questão Social", no entanto, acreditamos que o delineamento da categoria sob o ponto de vista marxiano é inteiramente possível, na exata medida em que seu construto teórico o pensador alemão nos fornece uma análise aprofundada da sociedade burguesa. Por isso mesmo, Netto (2010) afirma que a lei da acumulação capitalista subentende a anatomia de nosso objeto de exame.

A literatura que trata o tema corriqueiramente a relacionou, de uma forma ou de outra, com "o conjunto de problemas econômicos, sociais, e políticos, produto da contradição capital $x$ trabalho" como discute Cardoso et al. (2000, p. 84). Então, pode-se perceber que seu surgimento emerge da contradição fundante do modo de produção capitalista, qual seja: a apropriação privada do trabalho realizado coletivamente.

$\mathrm{Na}$ fileira dos argumentos utilizados pelas correntes a se posicionarem contra a explicação marxista dessas questões, projeta-se a defesa de que em outros momentos históricos existiram problemas relacionados à fome, à pobreza, à desigualdade social, portanto todo modo de produção foi permeado por inúmeras formas de desigualdade. No entanto, em outros modos de produção era a escassez de recursos naturais para a produção que provocava a insuficiência de recursos materiais para sobreviver, no sistema capitalista, ao contrário, é a acumulação privada que provoca a fome e a miséria da população. (MARTINELLI, 2005).

Nesse sentido, para entender essa relação e a lógica da dinâmica capitalista, é necessário compreender que o capital, além de ter uma face monetária, é também uma relação social; portanto os movimentos de sua (re)produção afetam, com maior ou menor grau de intensidade, todo o tecido social na totalidade dos seus aspectos. Dessa forma, a abordagem marxista defende que com a expansão dos mercados e a inserção do desenvolvimento tecnológico na produção, a dimensão constante (máquinas, ferramentas, utensílios etc.) da composição orgânica do capital, estimula, no início, uma demanda crescente de força de trabalho (dimensão variável) no processo produtivo, mas, atingindo certo limite, essa necessidade se extingue.

Depois desse estímulo inicial, a expansão do capital com a abertura de mercados não aumenta a demanda e nem os salários, ao contrário, ativa a exploração da mão de obra utilizada 
por meio da extração da mais valia absoluta. Com a intensificação da produção ocorre, ao mesmo tempo, um processo de acumulação de capital e aumento de um contingente de indivíduos que sobraram no processo produtivo por não se integrarem às atividades na indústria ${ }^{2}$. Marx explica que,

[...] essa diminuição relativa de seu componente variável, acelerada de seu componente pelo crescimento desse último, aparece, inversamente, como um aumento absoluto da população trabalhadora, aumento que é sempre mais rápido do que o do capital variável ou dos meios que este possui para ocupar aquela. (MARX, 2013, p.705).

Nessa lógica, o modo de produção capitalista cria um contingente de indivíduos, chamado por Marx de exército industrial de reserva ou superpopulação relativa que se caracterizam por estar aniquilados do mercado de trabalho, ficando, por conseguinte, à margem da produção e consumo das mercadorias, mas podendo ser, ao mesmo tempo, recrutados conforme os interesses do capital. Em suas palavras, temos: "[...] uma população trabalhadora excedente, produto necessário da acumulação ou do desenvolvimento da riqueza, com base no capitalismo, essa superpopulação torna-se, por sua vez, a alavanca da acumulação capitalista". (MARX, 1984, p. 283).

Em resumo, a lei geral da acumulação capitalista consiste no aumento da população trabalhadora na mesma razão da reprodução do capital de modo que forma um contingente de indivíduos sobrantes e desnecessários para a produção, que não conseguem se inserir no mercado. Esse contingente cumpre ainda um outro papel: exerce pressão aos trabalhadores inseridos no processo produtivo para se submeter às mais absurdas condições de trabalho; o salário, por exemplo, é regulado por esse movimento de contração e dilatação do exército industrial de reserva.

\footnotetext{
2 Esse processo iniciou-se no período convencionado acumulação primitiva do capital que, de acordo com Marx, pode ser entendida como o processo histórico em que se desenvolveu a pré-história do capital, ou seja, um período em que se ampliou condições materiais para o surgimento das formas de relação de produção mais consolidadas do capital.
}

Com base nessa essência, o processo sócio-histórico da sociedade foi sendo tecido tendo por base o projeto da burguesia, impondo o sistema capitalista como ordem societária natural e imutável, muito embora houvesse sido este, historicamente, tensionado por sucessivas crises. Conforme explicam Netto e Braz (2009) os movimentos no modo de produção capitalista são influenciados pela forma como a dinâmica capitalista reage e suas crises e contradições, produzindo interações e articulações de acordo com seus interesses.

Como já foi sinalizado, a trajetória histórica do capitalismo foi tensionada por crises econômicas, e não é por acaso que ela é considerada constitutiva do desenvolvimento do capital. A dinâmica capitalista, até a segunda metade da década de 1960 do século XX possuía quatro principais fases: a estabilidade, a depressão, a retomada e o auge que se repetiam continuamente num movimento cíclico. A partir desse lapso temporal, as "[...] crises voltam a ser dominantes, tornando-se episódicas as retomadas." (NETTO; BRAZ, 2009, p. 214).

Entre os fatores que a impulsionam, poderíamos citar: a tendência à queda da taxa de lucros $^{3}$, quando se conforma a superprodução em meio ao subconsumo das mercadorias, a atuação político-organizativa da classe trabaIhadora ou, ainda, pelas desregulações locais, como a falência de uma empresa ou a queda de um governo que instabiliza o fluxo de consumo, acumulando mercadorias nos estoques, fazendo surgir uma onda depressiva de desemprego. (PIMENTEL, 2007).

Mas, se as crises foram uma constante na história, também conseguimos visualizar aqueles que procuraram solucioná-las. Assim, os capitalistas se articulam implementando saídas para elas a fim de reestruturar a organização da produção retomando o auge em que há um boom de consumo e, consequentemente, o aumento da taxa de lucro. No entanto, a crise é inerente à dinâmica do capital, consequentemente, a taxa

\footnotetext{
${ }^{3} \mathrm{O}$ capital possui uma tendência à queda da taxa de lucro. Isso porque à medida que um capitalista maximiza seus lucros, por meio da renovação na produção, seus concorrentes "imitam" essa inovação o que provoca o rebaixamento do valor das mercadorias e queda na taxa de lucro, explodindo uma crise no sistema. Isso se repete em todo o ciclo de crise, depressão, retomada e auge (MARX, 2013).
} 
de lucro tende a estar sempre flutuando para níveis diversos devido ao conjunto da produção dos capitalistas não obedecer a um controle racional. (PIMENTEL, 2007).

Mészáros (2002) nos apresenta os desdobramentos mais atuais sobre a crise econômica. Parte do pressuposto que o capital possui um controle sócio metabólico sobre a reprodução das relações sociais ao acumular trabalho excedente. No entanto, a referida crise coloca em prova essa dimensão, introduzindo a sociedade em um processo de colapso destrutivo. Não obstante, do ponto de vista da contradição, as saídas postas, inclusive com uma recorrência cada vez menos duradouras, podem levar a classe trabalhadora, dependendo do seu nível de organização, a um processo revolucionário que aponte para a conquista do poder em direção a conformação de uma nova ordem societária, na qual o livre desenvolvimento de um seja condição para o livre desenvolvimento de todos, como apregoou Marx.

A chamada crise de 1970, estrutural, a estender-se pela atualidade, foi causada pelas contradições inerentes ao capital que foram intensificadas e refletidas para outros países, cujos impactos se assentam nas particularidades e singularidades de cada formação social, econômica e política que desenvolveram. Assim, elas flutuam na esfera econômica fazendo para a estrutura interna do capital, não existindo assim soluções, e não podemos esquecer que exponencia a degradação da vida social. Nas palavras de Mészáros (2002, p. 202): "tipicamente, as soluções propostas nem sequer arranham a superfície do problema, sublinhando, novamente, que estamos à frente de uma contradição interna insolúvel do próprio capital".

A partir dessas compreensões podem sobressair algumas expressões das transformações macro societárias, dentre as quais damos ênfase ao fato de que as políticas keynesianas caíram em desuso, dando lugar a princípios neoliberais, nos quais destaca-se a desresponsabilização do Estado frente à sociedade ${ }^{4}$, e

\footnotetext{
${ }^{4}$ Tal deresponsabilização - cujo marco histórico se registra principalmente com o desenrolar da década de 1990 - se refere, principalmente, à transferência de atividades que deveriam ser executadas por esta entidade para setores da sociedade civil organizada, como educação e cultura, por exemplo.
}

tudo isso acompanhado por um processo de legitimação ideológica desse sistema, por meio do que Harvey (2005) denomina neoliberalização; além disso, o sistema produtivo adotado passa a ser o padrão Toyotista, embasado em uma produção mais flexível, cuja terceirização é, nas palavras de Druck (1999), a "porta de entrada" para a conformação de relações de trabalho cada vez mais precarizadas. Associado a isso, verificamos, ainda, um processo de mundialização, expansão do setor de serviços e do sistema financeiro, e por outro lado a questão social se expande e se cronifica, os trabalhadores perdem muitos direitos por meio de relações trabalhistas permeadas pela subcontratação, polivalência e flexibilização. (NETTO, 2010).

No aspecto cultural há uma revolução técnico-científica, em que os meios eletrônicos tornam-se a moeda de troca. Além disso, os aparatos midiáticos transformam a vida social em algo totalmente mercantilizado, com forte incentivo ao consumo desenfreado. No meio acadêmico começa-se a verificar a presença de concepções pós-modernas que defendem a existência de uma crise de paradigmas, da racionalidade burguesa como tendência dominante, acompanhada de uma suposta crise do marxismo, dando lugar ao estudo do fragmentário, "do micro", do aqui e agora, com total rejeição das metanarrativas e grandes teorias explicativas da realidade. (NETTO, 2010).

Nesse ínterim, a Questão Social passa a ser vista como algo natural e irreversível no âmbito da vida social. As lutas sociais, que também representam uma expressão da mesma, provoca uma reação repressiva por parte do Estado, muito parecida com a que se tinha em meados da década de 1930 em que a luta da classe trabalhadora era tratada como "caso de polícia".

Os pesquisadores que se voltam para esses movimentos acompanham uma tendência metodológica de estudo deslocada dos processos sociais, ao mesmo tempo em que lançam as interpretações em um campo mais genérico, sem considerar as particularidades de cada espaço. Isso resulta em interpretações como as que embasam o conceito de excluído/incluído, identificando a pobreza como etapa transitória do indivíduo que por meio do mérito pode se inserir no mercado. (NETTO, 2010). 
É importante destacar que a base dessas transformações macros societárias estiveram no desmonte do Estado de Bem-Estar social, incentivado pela crise de 1970. Tratou-se de uma crise de realização, causada por uma queda brusca na produção e no consumo. Essa crise lançou o sistema em um imperialismo militar encabeçado pelos EUA; em uma exportação de capitais e a incorporação de sociedades como União Soviética nessa ótica (sociedade pós-capitalistas); além da intervenção estatal, desenvolvimento político de pleno emprego; isso favoreceu a autoexpansão do capital. (NETTO, 2010).

Conforme aponta Bihr (1999), esse período foi caracterizado pela efervescência da luta dos trabalhadores. No entanto, os mesmos acordaram uma série de direitos sociais oferecidos pelo Estado de Bem-Estar social e trocam por aquilo que o autor chama de "Grande noite", ou seja, a revolução, pela "alternativa". Noutras palavras: eles abandonam o projeto societário que vinha sendo gestado entre os setores trabalhistas em razão de um acordo com os estratos de classe que representam a burguesia; esta última, por sua vez, se vê obrigada a "dar os anéis para não perder os dedos", ou seja, a reconhecer e instaurar alguns direitos sociais para permitir a (re) produção do sistema de metabolismos do capital.

Obviamente que, se de um lado, o potencial político-organizativo da classe trabalhadora é uma dimensão presente, dada a práxis criadora do homem, de outro, não podemos desconsiderar que este sujeito encontra-se em conjunturas mais ou menos favorecedoras da luta social. Uma coisa é certa: ainda que, particularmente no tempo presente, queira-se extinguir a capacidade de articulação e luta da classe trabalhadora, nos filiamos a Mészáros (2002) e afirmamos que, cotidianamente, a classe trabalhadora tem (re) inventado sua luta, em razão de seus interesses, que são os da grande maioria da sociedade.

Muito embora o período em tela tenha sido de muitas conquistas para o conjunto de homens e mulheres que vivem da venda de sua força de trabalho, a classe operária acreditou em uma ideia de reformas dentro do Estado e pagou caro, visto que o capitalismo monopolista acirrou as contradições e determinações que concorreram para promover o agudizamento da Questão Social, ao passo que as respostas a ela ocorrem, de maneira pífia, apenas em suas refrações, pois atingi-la em seu cerne daria fim ao sistema de metabolismos do capital e, nem de longe, a burguesia quer cogitar essa possibilidade. Trata-se, então, de delimitar uma forma de concebê-la descolada da totalidade contraditória das relações sociais hauridas com o capitalismo a priorizar, sobretudo, sua administração e controle, dentro dos marcos regulatórios do capital.

\section{Neodesenvolvimentismo e as principais tendências das Políticas Sociais no Brasil de Lula e Dilma}

Tendo discutido sobre a anatomia da Questão Social e as principais discussões em torno dela, essa seção volta-se para a reflexão sobre o desenvolvimento sócio-histórico das Políticas Sociais, relacionando-as com o avanço do $\mathrm{Ne}$ odesenvolvimentismo e dos governos petistas Lula e Dilma.

Nesse sentido, segundo Behring (2007) as primeiras iniciativas de Políticas Sociais começaram entre os trabalhadores quando organizavam caixas de poupanças na Alemanha, no século XIX. Essa organização surgiu da solidariedade entre os operários no interior das fábricas em casos em que seus companheiros ficavam doentes ou quando morriam. A partir disso, a Política Social seguiu dois modelos de seguridade: o modelo Bismarckiano (que deu origem à contribuição prévia mediante contrato) e modelo Beveridgiano (calcado em princípios de universalidade) e teve suas protoformas em ações sem fins lucrativos, isto é, filantrópicas, que buscavam a salvação do indivíduo pelo agir com bondade e caridade.

Nesse ínterim, as políticas sociais ganharam novas conotações do fim século XIX para o início do século $X X$, quando os argumentos liberais de organização socioeconômica foram questionados diante do contexto instaurado com a crise de 1929. Essa crise - cujo marco histórico é a quebra da bolsa de Nova York, em 1929 atingiu, de diversas formas, todo o mundo, ao mesmo tempo em que favoreceu o questionamento da legitimidade política e as bases que, até então, davam sustentação ao capitalismo. Sua principal causa esteve nas mudanças no ciclo capitalista de produção, em que houve uma queda da taxa de produção, devido à superprodução. Sendo superados esses percalços, as 
políticas sociais se multiplicam, lançando uma tendência de expansão conformando o período chamado de Welfare-State. É importante considerar que o modelo liberal caiu não só por causa da crise, mas também a revolução socialista na Rússia e o processo de reconhecimento de direitos influenciaram o fim desse parâmetro político. (BERHING, 2007).

As principais saídas colocadas à crise assentaram-se na intervenção do Estado na economia, garantindo, assim, a livre circulação do mercado. Como consequência disso, surgiram as fusões de empresas constituindo oligopólios. O pacto que ficou conhecido como pacto Fordista-Keynesiano, reunindo o modo de produção em série promovido pelo fordismo e a intervenção do Estado defendido pela doutrina Keynesiana. Esse período ficou conhecido como anos de ouro do capitalismo por conta de sua ascensão e pela fase de pleno emprego para os trabalhadores, além da consolidação das políticas sociais sistematizadas e colocadas como competência do Estado (BERHING, 2007). Nesse contexto, o Estado associa suas funções a administrar a economia, garantindo, assim, a produção, além de proteger os considerados incapazes, tais como crianças e idosos, com políticas direcionadas ao segmento.

No entanto, esse período de anos de ouro começa a dar sinais de esgotamento, no final da década de 1960, com uma queda da taxa de lucro provocada pelo desemprego advindo da introdução de novas tecnologias, o que gerou aumento do preço de produtos no mercado. Além disso, a inflação subiu e o processo de endividamento cresceu gradativamente. Para superar essa crise, ajustes estruturais foram realizados, nos quais o Estado atuou como "almofada amortecedora anticrise" (BERHING, 2007, p.86). Mesmo assim, a crise tomou enormes proporções, reconfigurando toda a sociedade, e com isso o Estado passou por outra mudança, retomando, sob novos moldes, os aspectos do liberalismo ${ }^{5}$.

\footnotetext{
${ }^{5}$ A título de observação, no período da segunda grande crise (1970) do capital, o Liberalismo vai ganhar novas feições e determinações que se pautam nas características que envolvem o período histórico em que surge. A retomada desses pressupostos dar-se-á, agora, por meio do chamado de Neoliberalismo, e essa ideologia emergiu com a sociedade de MontPéleren, e se expressa, sobretudo, com o livro O Caminho da Servidão, de Friedrich Hayek, após a Segunda Guerra Mundial (ANDERSON, 1995, p. 10).
}

De acordo com Netto (1996) operou-se, a partir de 1970, transformações nas tendências econômicas mundiais em que o capital se mundializa. Constitui-se como características dessa conjuntura mudanças no mundo do trabalho, com diversos rebatimentos para a classe trabalhadora, dos quais se registra, a título de exemplo, a perda de direitos, o aumento da jornada de trabalho, bem como a flexibilização e desregulamentação das condições e relações trabalhistas. Conforme essas transformações ocorrem, a questão social se alarma e se complexifica, a organização da classe trabalhadora torna-se dificultosa e, além disso, o conjunto de problemas sociais cresce: chegamos ao estágio denominado por Netto (2009) de barbárie social.

As políticas sociais nesse cenário ganharam caráter minimalista, restritivo e seletivo, sofrendo um processo de sucateamento, enquanto o sistema privado se expande substituindo o público. Ao mesmo tempo em que isso ocorre, o chamado "terceiro setor" vai ganhando destaque com o desenvolvimento de práticas assistencialistas e pontuais, de cunho caritativo, realizadas pela sociedade civil. Essa atuação fomenta ainda mais o afastamento do Estado de seu compromisso com o social.

No Brasil, as políticas sociais seguiram essas mesmas tendências, obviamente que resguardadas algumas particularidades presentes em nosso processo de formação econômica, social e política, como demonstra Prado Júnior (s/a).

Entre nós, o desenvolvimento dos mecanismos de proteção social esteve atrelado a um contexto de intensa participação popular, a exigir o reconhecimento de diversos direitos sociais. Esse movimento desembocou na construção da Constituição Federal de 1988, a chamada "constituição cidadã". No entanto, também nesse contexto histórico ganhavam corpo, em nossa particularidade, as tendências neoliberais, atingindo a proposta de garantia de direitos propostos pela Constituição Federal à medida que substituiu o universalismo protetor pelo particularismo social. A América Latina também seguiu essas tendências, assim como os EUA e Caribe, além de, fora desse marco, países da Europa. (BOSCHETTI, 2012).

Dentre outras instâncias, essas tendências neoliberais se fazem visíveis e se refletem no processo de restrição de recursos para as 
políticas públicas. O Projeto de Lei Orçamentário Anual previsto para 2014 prevê quase a metade do orçamento $(42,42 \%)$ para juros e amortizações da dívida. Esse dinheiro, segundo informações transmitidas pela auditoria da dívida, corresponde a 10 vezes o valor oferecido para a saúde, 12 vezes para a educação, 4 vezes para os servidores federais e 192 vezes o que seria destinado para a Reforma Agrária ${ }^{6}$.

Em verdade, o direcionamento e a finalidade de parte dos recursos destinados ao pagamento de juros e às amortizações da dívida deixam expostas as opções políticas que direcionam o Estado brasileiro, além de evidenciar o lugar de subalternidade ocupado pelas políticas sociais em meio aos ordenamentos da elite financeira mundial e nacional. Esses números deixam explícito como os gastos sociais, de acordo com a conjuntura econômica a assolar cada época, são facilmente desconsiderados, tornando-se uma espécie de válvula de escape para socorrer o capital sempre que ele não tem de onde tirar dinheiro para amenizar as contradições que nascem de seu interior.

Não nos enganemos: em períodos de acirramento e de arrocho financeiro, a burguesia não terá dúvidas ou hesitará em determinar para qual lado ele deve pender: a classe trabalhadora é seu alvo primeiro e, nesse sentido, também sofrerá mais cedo as consequências desse processo (MARX; ENGELS, 1999). Isso provoca o esfacelamento das políticas públicas e, consequentemente, a precarização das condições de vida da classe trabalhadora, na medida em que se tornam fragmentadas e cada vez mais minimalistas e seletivas, com chances de servir a vícios enraizados na cultura brasileira, como o apadrinhamento, o favor, o "voto de cabresto". Isso revela, no que toca, por exemplo, ao Sistema Único da Assistência Social (SUAS) que, colocado como algo humanizador e moderno, reitera as arcaicas relações de submissão e vícios politiqueiros, transformando em favor aquilo que seria um direito social.

Mesmo assim, se alardeia aos quatro cantos do país o expressivo aumento nos indicativos conquistados nos últimos dez anos - marco tem-

\footnotetext{
${ }^{6}$ Disponível em: http://www.andes.org.br/andes/print-ultimas-noticias.andes? $\mathrm{id}=6538$. Acesso em 08 de jan. 2014.
}

poral em que o Partido dos Trabalhadores (PT) tem estado à frente da direção social, econômica e política deste país. Não podemos e nem é nossa pretensão desconsiderar que alguns programas e medidas adotadas pelo governo federal, no lastro das repetidas sucessões petistas, primeiro com Lula e depois com Dilma, foram importantes, mas queremos chamar a atenção para o fato de que elas carregam algumas contradições reveladoras da limitação existente em querer priorizar o status da cidadania como fim último, até porque a própria condição de "ser cidadão" é moldada de acordo com determinados interesses.

Isso é facilmente constatável quando se leva em consideração que, na contemporaneidade, um pobre necessita ter uma renda mensal de um pouco mais de 120 reais para se enquadrar em tal status e de 70 reais para ser considerado extremamente pobre. Vale destacar que há pouco tempo que o governo federal baixou o critério básico que define esse status de pobreza social no país.

O Relatório sobre as cidades latinoamericanas do Programa das Nações Unidas para os Assentamentos Humanos (ONU-Habitat), publicado em 2012, revela como os números baixaram: apenas $20 \%$ da população brasileira vive na pobreza e indigência considerando as taxas de pobreza urbana. Quando, em 2002, só o número de indigentes era 32 milhões de brasileiros, 17,3 milhões eram de uma das regiões mais pobres do país, a Região Nordeste. O Instituto de Pesquisa Econômica (IPEA) lançou, em 2012, o dado de que 3,5 milhões de brasileiros saíram da pobreza, tendo 15,7 milhões ainda permanecido nesta condição. Em 2002, eram 41 milhões de pobres.

No entanto, da aparência à essência, percebemos que os números não são totalmente positivos: por trás deste discurso de rebaixamento dos índices de pobreza, perduram dificuldades em outras dimensões da vida, a exemplo do acesso à saúde, educação e transporte. Isso quer dizer que as políticas de transferência de renda aumentaram de fato os indicadores de poder aquisitivo e, consequentemente, de consumo. No entanto, a qualidade de vida da população ainda continua precária e a desigualdade social prevalece.

Nesse sentido, o Índice de Gini calcula a desigualdade social no país de acordo com a 
renda per capita das famílias. Este índice tem demonstrado uma queda entre 1995 e 2009, no entanto, de acordo com Freitas et al., esse fato não tem relação com a expansão de benefícios, pois a análise comparativa demonstra que com ou sem benefícios o Índice de Gini continua muito aproximado, com uma margem pequena de diferença. Conforme sua análise, essa queda ocorreu, no Brasil, com a motivação

mais dos salários e aposentadorias indexados pelo salário mínimo do que pelas transferências de renda, que ocupam um papel secundário, até porque seu montante - individual, no caso do BF, e em termos da renda total para o $\mathrm{BF}$ e o $\mathrm{BPC}$ - mostra-se bastante reduzido. (FREITAS, et. al. 2012, p.62)

A pesquisa de Freitas et al. (2012) comprova que a queda do Gini com ou sem benefícios nas regiões rurais são aproximadas, entre 1995 e 2009 era de $9,52 \%$ sem benefícios e $9,31 \%$ com benefícios, entre 2003 e 2009, sem benefícios $7,91 \%$ e com benefícios $7,89 \%$. Na zona urbana essa queda se manteve: entre 1995 e 2009, sem benefícios foi de $7,66 \%$ e com benefícios, $8,03 \%$; e entre 2003 e 2009 a percentagem sem benefícios representava $6,34 \%$ e com benefícios, $6,63 \%$. Na Região Nordeste, entre 1995 e 2009, sem benefícios $7,07 \%$ e com benefícios $7,37 \%$, e entre 2003 e 2009, sem benefícios caem 4,59\% e com benefícios $4,78 \%$.

O movimento histórico que leva Lula da Silva à presidência da república, nos anos 2000 , foi permeado de tensões e contradições, pois, se de um lado, sua campanha foi construída sob o signo da luta de classes a assolar e incentivar, sobretudo entre os setores operários do $A B C$ paulista, a necessidade de ultrapassagem da ordem capitalista, de outro, os rumos trilhados depois da vitória desviaram-se do caminho pensado coletivamente no lastro daqueles anos. Consoante Ruy Braga (2012, p. 24):

O governo petista quase imediatamente racionalizou, unificou e ampliou o programa de distribuição de renda conhecido como Bolsa Família, transformando a luta social contra a miséria e a desigualdade em um problema de gestão de políticas públicas.

A análise de Braga nos esclarece sobre uma espécie de ressignificação negativa governo sob o comando de Lula. Atender aos interesses do capital, sem desconsiderar ou invisibilizar algumas demandas oriundas dos extratos mais pauperizados da sociedade: essa parece ter sido a tônica do direcionamento dado ao governo pelo PT. Nesse sentido, a luta de classes é evitada ao máximo e passa a ser transformada num falso acordo, marcado pela "conciliação de classes", como sugerem alguns analistas. Ao passo em que isso acontece, sob diversas formas, das quais é exemplar a cooptação de determinados movimentos sociais, as possibilidades de transformação radical da sociedade vão sendo relegadas a último plano.

Essa conjuntura conforma o que Francisco de Oliveira vem denominando "hegemonia às avessas". Trata-se, em sua análise, de criar o terreno ideológico em que as classes populares estão aparentemente conseguindo imprimir a "direção moral" do governo quando, na verdade, elas se tornam cada vez mais submissas aos ditames do grande capital. Para o sociólogo, o Programa Bolsa Família tem cumprido um papel de extrema relevância na materialização deste fenômeno. Em suas palavras:

Chegando ao poder, o PT e Lula criaram o Bolsa-Família, que é uma espécie de derrota do apartheid. Mais ainda: ao elegermos Lula, parecia ter sido borrado para sempre o preconceito de classe, e destruídas as barreiras da desigualdade. Ao elevar-se à condição de condottiere e de mito, como as recentes eleições parecem comprovar, Lula despolitiza a questão da pobreza e da desigualdade. Ele as transforma em problemas de administração, derrota o suposto representante das burguesias - o PSDB, o que é inteiramente falso - e funcionaliza a pobreza. A pobreza, assim, poderia ser trabalhada no capitalismo contemporâneo como uma questão administrativa (OLIVEIRA, 2010, p 24-25).

Certamente, não é apenas o BF, isoladamente, que tem adquirido relevância no governo Lula, mas o conjunto da Assistência Social, de modo geral, tem apresentado-se como central e, muitas vezes, isso tem acontecido em detrimento das outras políticas que compõem a seguridade social, como se fosse o "arrimo" da proteção social brasileira. De nossa parte, entendemos ser a Assistência Social uma das formas de atuação do Estado em meio às múltiplas expressões da 
"questão social" e que seu desenvolvimento é funcional ao capitalismo, na exata medida em que permite "um elo entre a produção e reprodução [...] pela via da cidadania [...] constituem num mecanismo ideológico por excelência" (MOTA, 2010, p.17).

Obviamente, esta não é uma característica única da Assistência, mas de todas as políticas sociais, haja vista serem forjadas na dinâmica das relações a partir das tensões entre sociedade civil e sociedade política. Contudo, dado o papel desempenhado por ela, desde a eleição de Lula, consideramos pertinente dar-lhe maior destaque.

A partir da década de 1990, a Assistência Social passou por um processo de expansão após a criação do SUAS, em 2004, e o desenvolvimento dos programas de transferência de renda, principalmente o conhecido Programa Bolsa Família nos Governos Lula e, posteriormente, no Governo Dilma. Isso fez com que o Estado formulasse e consolidasse toda uma rede sócio-assistencial ativa. (SITICOVSKY, 2010).

Coexistem muitas polêmicas em torno do Bolsa Família. Diversos setores da sociedade têm emitido opiniões variadas, muitas divergentes. Alguns argumentam que esse programa está acomodando os indivíduos, não estimulando as pessoas a conseguir um emprego. Assim, acreditam que a quantia em dinheiro recebida é capaz de atender as necessidades básicas, de modo a tornar o exercício do trabalho opcional. Ou seja: o governo está dando o "peixe" à classe trabalhadora e, por isso, eles não precisam "aprender a pescar".

Esse discurso não é pertinente, pois o programa de transferência de renda não desestimula o trabalho, assim como as outras classes que possuem condições de consumir e não se acomodam. Além disso, uma média de $74,5 \%$ de pessoas que são beneficiadas trabalha, de acordo com a pesquisa de Marcelo Medeiros, Tatiana Brito e Fábio Soares em 2007 apud Singer (2009). Mas, essa pesquisa evidencia que há uma tendência à popularidade do Partido dos Trabalhadores que angaria votos nas eleições.

No lastro de argumentações, outros se posicionam parcialmente adversos ao referido programa pelo seu caráter assistencialista e por desmobilizar a classe trabalhadora na busca pela expansão dos direitos sociais e pela superação da emancipação política. Também existem seg- mentos da sociedade que, apesar de todas as críticas, reconhecem alguma importância no BF, pela capacidade de "colocar o pão na mesa da classe trabalhadora", de sanar algumas necessidades mais imediatas.

Diante da exponenciação das expressões da questão social, observamos a utilização de estratégias que consigam abrandar a classe trabaIhadora e suas possíveis formas de organizações e reivindicação. Por vezes, essas estratégias incidem não apenas no plano material, adentrando no universo mais subjetivo e "fantasioso" da vida social. Certamente o chamado neodesenvolvimentismo está fortemente apoiado nesse universo ideológico, pois ainda que queiram dar uma nova significação morfossintática, na prática verificamos uma continuidade e aprofundamento das estratégias neoliberais e, consequentemente, a manutenção do status quo vigente.

Lula, então candidato nas eleições de 2012, propôs uma administração que iria mudar a política econômica, lançar estratégias para pagamento da dívida externa, reduzir o domínio da burguesia internacional no país e, com isso, ganhou as eleições. No entanto, deu continuidade de maneira aprofundada ao que já vinha embalando seu governo nos anos precedentes, ou seja, prosseguiu disseminando diversas medidas econômicas inspiradas no neoliberalismo. No Governo Lula a dívida interna chegou a 1 triIhão, considerando os juros, e o então presidente deu prioridade de investimento ao agronegócio e realizou uma Reforma na previdência e na tributação que só beneficiou o setor privado de serviços. (FREITAS, 2007).

De toda forma, poucos são os consensos acerca da discussão sobre a orientação econômica que norteou os dez anos do Partido dos Trabalhadores no Brasil. Já se pensou em desenvolvimentismo, nacional-desenvolvimento, neodesenvolvimentismo e pós-neoliberalismo. Compartilhamos da ideia de Pereira (2012), logo, iremos nos referir ao neoliberalismo quando nos reportarmos ao modelo político e econômico no Brasil após a ditadura militar, que implementaram medidas relacionadas aos ideários do referido sistema. Nas palavras da autora: "nenhum governo brasileiro pós-ditadura militar, e eleito diretamente pelo povo, rompeu com os mandamentos neoliberais, nem mesmo os que se identificavam com a esquerda" (p. 740). 
A crítica ao desenvolvimento iniciou-se com uma publicação da autora Miriam Limoeiro Cardoso, logo em seguida Florestan Fernandes também lançou publicações nesse sentido. Estávamos em um regime ditatorial, portanto, essas críticas não foram aceitas, resultando no exílio dos dois autores. (LEHER, 2012).

Isso paralisou essa discussão, que logo foi substituída pelo neoliberalismo que entrou em voga. No entanto, esse modelo político passou por inúmeras crises nos governos latino-americanos que o implementaram. A ideologia do desenvolvimento foi colocada como oposta ao neoliberalismo, pois os últimos eram hostis à ideia de intervenção estatal, e, desse modo, passaram a explicar o desenvolvimento como pós-neoliberalismo. (LEHER, 2012).

O ex-ministro Luiz Bresser Pereira discute a existência de um novo desenvolvimentismo. Ele o caracteriza como corrente que defende a "maior abertura ao comércio internacional; maior investimento privado na infraestrutura e maior preocupação com a estabilidade econômica" (CASTELO, 2012, p. 624).

No entanto, no "frigir dos ovos" em defesa do desenvolvimento no país "os setores financeiros operaram vultuosos e lucrativos empréstimos que aprofundaram a condição capitalista dependente do país vis-à-vis ao núcleo hegemônico do capitalismo." (CASTELO, 2012, p. 11)

\section{Considerações finais}

No tempo recente, a complexificação da questão social nos marcos da sociedade capitalista, em sua fase imperialista, tem trazido à tona inúmeras dificuldades para a classe trabaIhadora, expressando-se, entre outros aspectos, nas configurações determinantes das políticas sociais, cujas características, nos tempos de "neodesenvolvimentismo", se fazem visíveis pela via da restrição, focalização e seletivização - para citar apenas algumas. Nesse contexto e, particularmente, na realidade brasileira, a ascensão do Partido dos Trabalhadores ao poder poderia significar uma mudança substantiva para as mulheres e homens que vivem do trabalho, mas não foi isso que ocorreu.

Destarte, as políticas sociais inspiradas no formato e intencionalidade orientados pela concepção da Nova Questão Social e aliadas à cultura brasileira de favor e apadrinhamento, que são endossadas pela precarização das políticas sociais, constrói a base de manutenção do poder dos governos petistas à medida que angaria votos dentro dos grandes bolsões de miséria no país, que enxergam nos benefícios de transferências de renda uma fonte de renda e reprodução de sua existência.

Verificamos, nesse contexto, uma dualidade, a se expressar, de um lado, na propaganda ideológica que assegura, no lastro dos últimos 10 anos, termos melhorado as condições de vida - discurso este assentado sobremaneira na expansão dos programas de transferência de renda. De outro, verificamos a pequena mudança para os setores pobres e despossuídos. Ou seja, a questão social está cada vez mais complexa e as formas de espraiar suas refrações não se fazem na medida do necessário, mas, ao mesmo tempo, criou-se o terreno ideológico ideal para acalmar a classe trabalhadora.

A hegemonia, realmente, está às avessas. É preciso, mais que nunca, de coragem e ousadia para enfrentar as determinações contemporâneas e fundar uma nova hegemonia, uma contra-hegemonia capaz de dar fim ao capitalismo e, com ele, à questão social.

\section{Referências}

ANDERSON, P. Balanço do Neoliberalismo. In: SADER, E.; GENTILI, P. (Orgs.). Pós-neoliberalismo: as políticas sociais e o Estado democrático. Rio de Janeiro: Paz e Terra, 1995.

BEHRING, E. R. Política Social: fundamentos e história. 2. ed. São Paulo: Cortez, 2007.

BOSCHETTI, I. América Latina, Política Social e Pobreza: "novo" modelo de desenvolvimento? In: SALVADOR, E. et. al. (Orgs.). Financeirização, fundo público e política social. São Paulo: Cortez, 2012.

BRAGA, R. A política do precariado: do populismo à hegemonia lulista. São Paulo: Boitempo, 2012. (Coleção Mundo do Trabalho).

CARDOSO, F. G. et al. Questão Social: fenômeno vinculado à histórica luta de classes e determinante básico do Serviço Social como profissão. In: Revista semestral do Programa de Pós-Graduação em Política Social do Departamento de Serviço Social da UnBN, n. 6, janeiro a junho de 2000. 
CASTELO, R. O novo desenvolvimentismo e a decadência ideológica do pensamento econômico brasileiro. Serviço Social \& Sociedade, São Paulo, n. 112, p. 613-636, out./dez. 2012.

FREITAS, G. G. et al. Brasil real: a desigualdade para além dos indicadores. 1. ed. São Paulo: Outras expressões, 2012.

FREITAS, R. C. O governo Lula e a proteção social no Brasil: desafios e perspectivas. Revista Katálysis, Florianópolis, v. 10, n. 1, p. 65-74, jan./jun. 2007.

LEHER. R. Ideologia do desenvolvimentos, pobreza e hegemonia. In: Desenvolvimentismo e construção de hegemonia. São Paulo: Cortez, 2012.

MARTINELLI, M. L. Serviço Social: identidade e alienação. 13. ed. São Paulo: Cortez, 2005.

MARX, K. O capital: crítica da economia política: Livro I: o processo de produção do capital. São Paulo: Boitempo, 2013.

O capital: crítica da economia política. São Paulo: Abril Cultural, 1984. L. Primeiro, Tomo 2.

MARX, K.; ENGELS, F. Manifesto do Partido Comunista. São Paulo: Pocketedition, 1999.

MÉSZÁROS, I. Para além do capital: rumo a uma teoria da transição. São Paulo: Boitempo, 2002.

MOTA, A. E. O fetiche da Assistência Social. In: MOTA, A. E. (Org.). O Mito da assistência social: ensaios sobre estado, política e sociedade. São Paulo: Cortez, 2010.

NETTO, J. P. Capitalismo Monopolista e Serviço Social. São Paulo: Cortez, 1992.

Uma face contemporânea da Barbárie. Comunicação no III Encontro Internacional "Civilização ou Barbárie", SERPA, 2010.

NETTO, J. P.; BRAZ, M. Economia política: uma introdução crítica. 5. ed. São Paulo: Cortez, 2009.

OLIVEIRA, F. Hegemonia às avessas. In: OLIVEIRA, F.; BRAGA, R.; RIZEK, C. (Orgs.). Hegemonia às avessas: hegemonia, política e cultura na era da servidão financeira. São Paulo: Boitempo, 2010.

PEREIRA, P. A. P. Utopias desenvolvimentista e políticas sociais no Brasil. Serviço Social \& Sociedade, São Paulo, n. 112, p. 613-636, out./dez. 2012.

PIMENTEL, E. Uma "nova questão social"? Raízes materiais e humano-sociais do pauperismo ontem e hoje. Maceió: EDUFAL, 2007.
PRADO JÚNIOR, C. Formação do Brasil contemporâneo. São Paulo: Brasiliense, s/a.

SINGER, A. Raízes sociais e ideológicas do lulismo. Revista Novos Estudos, n. 85, nov. 2009.

SITCOVSKY, Marcelo. Particularidades da expansão da assistência social no Brasil. In: MOTA, A. E. (Org.). O Mito da assistência social: ensaios sobre estado, política e sociedade. São Paulo: Cortez, 2010. 